\title{
Combined immunodeficiency due to ZAP70 deficiency
}

INSERM

\section{Source}

INSERM. (1999). Orphanet: an online rare disease and orphan drug data base. Combined immunodeficiency due to ZAP70 deficiency. ORPHA:911

Combined immunodeficiency due to ZAP70 deficiency is a very rare, severe, genetic, combined immunodeficiency disorder characterized by lymphocytosis, decreased peripheral CD8+ T-cells, and presence of normal circulating CD4+ T-cells, leading to immune dysfunction. 